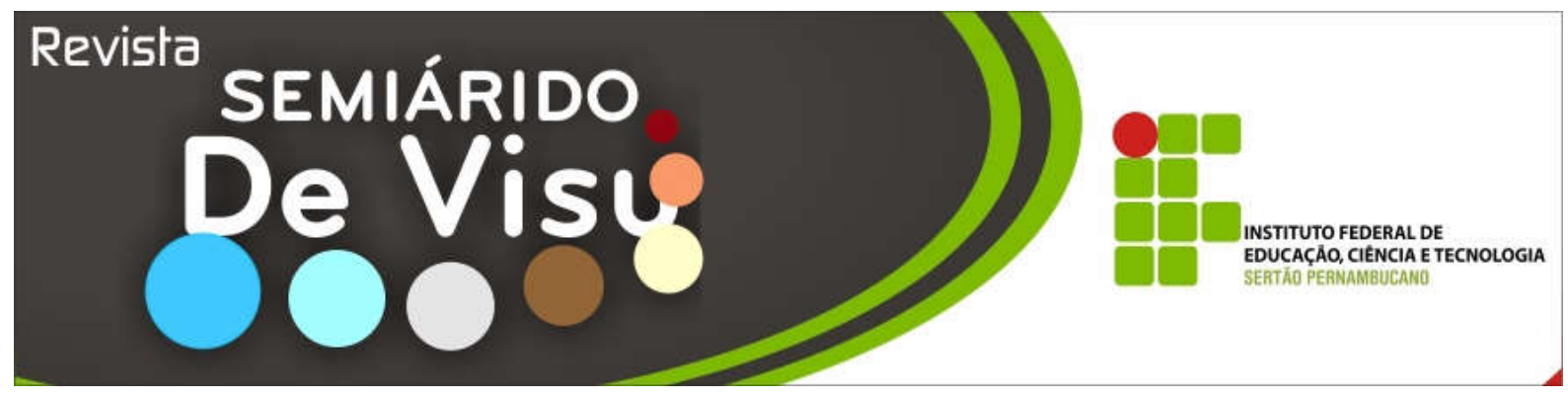

\title{
Caracterização de produtores e consumidores de produtos agroecologicos do município de Ouricuri-PE
}

\author{
Farnezio de Castro Rodrigues ${ }^{1}$, Aroldo Gomes Filho ${ }^{2}$, Adelson Dias de Oliveira ${ }^{2}$, Claudiana Maria \\ da Silva ${ }^{3}$ \\ ${ }^{1}$ Mestrando do Programa de Pós-Graduação em Tecnologia Ambiental - ITEP. Fone (87) 99227385 \\ - e-mail: farnezio.castro@,ifsertao-pe.edu.br \\ ${ }^{2}$ Docentes do Instituto Federal de Educação, Ciência e Tecnologia Sertão Pernambucano - Campus \\ Ouricuri. E-mail: aroldo.gomes@ifsertao-pe.edu.br adelson.dias@ifsertao.edu.br \\ ${ }^{3}$ Discente do Institu to Federal de Educação, Ciência e Tecnologia Sertão Pernambucano - Campus \\ Ouricuri
}

RESUMO: Este trabalho tem como objetivo caracterizar os produtores e consumidores agroeco ló gicos e convenc ionais do município de Ouricuri-PE, utilizando para essa pesquis a questionários, sendo estes submetidos aos entrevis tados, visando com isso, gerar um melhor mapeamento da agricultura agroecológica e de consumo deste produtos neste município. Os resultados obtidos com este trabalho demons tram que, os produtores agroecologic os apres entam quanto ao gênero $50 \%$ do sexo masculino e $50 \%$ do sexo feminino, com idade entre 29-38 anos e com renda média mensal de 1 salário mínimo, a lém de contarem com o apoio de ONGs na prestação de assistência técnica. Com relação aos consumidores agroecoló gicos estes são em sua maioria do sexo feminino (73,33\%) enquanto que apenas $26,66 \%$ destes são do sexo masculino, ambos possuindo idade entre 29-38 anos, com uma renda familiar em média de 1 salário mínimo. Com relação aos consumidores de produtos convencionais, $14,89 \%$ destes apresentam sexo masculino, enquanto que $85,1 \%$ são do sexo feminino, com fa ixa etária de 29-38 anos e uma renda familiar de 1 salário mínimo.

Pala vras - chave: Co mercialização, estudo de merc ado e valor nutritivo.

\section{Characterization of producers and consumers of the municipality of agroecological Ouricuri-PE}

\begin{abstract}
This study aims to characterize the producer and consumer of ecological and conventional Ouricuri-PE munic ipality, us ing questionnaires for this research, which are submitted to respondents in order to thereby generate data that seek a better mapping of agriculture and agro-ecological products in this municipality. The results obtained in this study show that agroecological producers have in terms of gender 50\% male and 50\%, aged 29-38 years with an average monthly income of minimum wage, and rely on the support of ONGs in providing technical assistance. With regard to consumers agroecological these female (73.33\%) while only $26.66 \%$ are male, aged $29-38$ having both years, with are mostly an average hous ehold income of 1 salary minimum. With regard to cons umers of conventional products, $14.89 \%$ of those are male, while $85.1 \%$ are female, aged between $29-38$ years and a family income of a minimum wage.
\end{abstract}

Key words: Marketing, market research and nutritional value. 
(RODRIGUES et al., 2015)

\section{Introdução}

tualmente
relacionados ao meio ambiente, à
saúde dos agricultores
consumidores, promovidos por malefícios causados pelos agrotóxicos na etapa do cultivo, têm preocupado grande parte da população mundial no consumo de alguns alimentos. A agricultura baseada no uso de recursos não renováveis e em sistemas monoculturais mecanizados causa sérios problemas ambientais. O uso abusivo de insumos químicos e o afastamento de trabalhadores rurais do campo têm sido há muito tempo uma das críticas a esse tipo de agricultura.

Nesse contexto, a agricultura agroecológica, ao evitar as consequências ambientais negativas trazidas pelo modelo agrícola atual, tem gerado grande interesse da comunidade acadêmica nos estudos de diferentes estilos de agricultura alternativa. Nos modelos agrícolas sustentáveis, a proposta é utilizar os recursos disponíveis na propriedade rural, evitando os adubos químicos e a consequente degradação ambiental, resgatando a sabedoria popular e dando condições de sobrevivência e qualidade de vida para o agricultor no meio rural.

Sistemas de produção com bases agroecológicas, considerados sustentáveis, podem ser caracterizados pelo uso de tecnologias que respeitem a natureza, ou seja, que, no trabalho com ela, sejam mantidas ou pouco alteradas as cond ições de equilíbrio entre os organismos participantes do processo de produção. Foi a partir destes princípios que foram desenvolvidas diferentes correntes de produção, dentre as quais a agricultura agroecológica tem sido a mais difundida, sendo reconhecida junto ao mercado como sinônimo de todas as outras (JESUS, 1985; COSTA, 1987; JESUS, 1996).

Nos últimos anos é crescente a demanda por produtos orgânicos proporcionada pelas exigências dos mercados, os anseios da sociedade em obter produtos naturais e a necessidade de preservação do meio ambiente e de garantia de vida às futuras gerações. Diante dessas condições, percebe-se que o mercado de produtos orgânicos, de um modo geral, é bastante expressivo e apresenta-se como uma proposta duradoura e auto-sustentável, privilegiando a qualidade de vida dos produtores, consumidores e a preservação ambiental (CUENCA et al., 2007).

A comercialização da produção agroecológica ainda é considerada difícil, pois além de atingir mercado relativamente simples, continua como atribuição do próprio produtor (ZOLDAN \& KARAM, 2004). Geralmente esse tipo de agricultura é mais compatível com a especificidade da agricultura familiar, por exigir maior necessidade de ocupação de mãode-obra. A venda desses produtos aparece como um dos grandes gargalos da cadeia produtiva e pode ser considerado o fator limitante para a reprodução socioeconômica de muitos agricultores familiares rurais do País. Segundo Souza et al. (1998), o produtor deve ser informado sobre os vários níveis de comercialização relacionados à questão de mercado, preço, tendência e qualidade do produto.

Para atingir um lugar no mercado os produtores precisam obter mais informações a respeito do que o consumidor pretende adquirir, e saber qual a percepção do consumidor sobre o seu produto final, sem esse entendimento não tem como o produtor permanecer no mercado, uma vez que este torna-se a cada dia mais competitivo. É pertinente evidenciar que nos últimos dez anos nota-se um crescimento constante das mulheres no mercado de trabalho e principalmente como arrimo de família seja no espaço urbano ou rural. Outro fator é o interesse por alimentação saudável inferindo diretamente nas dietas, que colaboram para alterar o padrão de consumo da população.

De acordo com Menezes (2002) os padrões de consumo de alimentos no Brasil estão em constantes mudanças, devido à alteração dos preços dos produtos, enquanto que para Regmi et al. (2004), as relaçõ es como produção e consumo não se baseiam apenas em fatores econômicos outros fatores como sociais, 
(RODRIGUES et al., 2015)

culturais e nutricionais também estão associados.

Segundo Saabor e Rojo (2001), para atender as exigências de mercado, é necessário traçar tanto o perfil dos produtores como os dos consumidores. O Brasil é um dos países com mais de 170 milhões habitantes que faz com que o este tenha um dos maiores mercados de consumidores do mundo.

Neste sentido este trabalho tem como objetivo apoiar os produtores na identificação dos problemas na produção agroecologica e também levar informações para o consumidor, informações estas que podem impactar na decisão final de compra do produto.

\section{Material e métodos}

O presente trabalho foi conduzido na cidade de Ouricuri-PE, município localizado na região do Araripe, mesorregião Sertão e na Microrregião de Araripina no Estado de Pernambuco, limitando-se ao norte com Araripina, Trindade e Ipubi, ao sul com Santa Cruz e Santa Filomena, a leste com Parnamirim e Bodocó, e a oeste com Estado do Piauí. A área municipal ocupa $2373,9 \mathrm{~km}^{2}$ e representa $2,25 \%$ do Estado de Pernambuco. A sede do município tem uma altitude aproximada de 451 metros e coordenadas geográficas de 07 52 '57' de latitude sul e 40 $04^{\prime} 54^{\prime \prime}$ de longitude oeste, distando $620,6 \mathrm{~km}$ da capital, cujo acesso é feito pela BR-232/316 (MINISTÉRIO DE MINAS E ENERGIA, 2005).

O trabalho foi desenvolvido com produtores agroecologicos no período de Junho a Agosto/2011, e com consumidores agroecologicos e convencionais de novembro/2011 a janeiro/2012 onde ambos foram entrevistados, utilizando-se de questionários com perguntas abertas e fechadas. Trata-se de uma pesquisa de base quantitativa, sendo o questionário o principal instrumento de coleta de dados. Foram selecionados dezesseis agricultores familiares e sessenta e dois consumidores, sendo estes quinze agroecológicos e quarenta e sete convencionais, as entrevistas foram realizadas de forma individual, em horários preestabelecidos, pela manhã. As questões para os produtores foram: gênero; escolaridade; faixa etária; valor da renda com a prática agroecológica; produção; tempo de cultivo e motivação; produtividade; satisfação com resultados econômicos e com as formas de comercialização; preços pagos pelo produto; problemas na propriedade e fatores limitantes para expansão do sistema. E para os consumidores tanto agroecologicos como convencional foram; gênero; faixa etária; escolaridade; renda familiar; número de moradores na residência; composição familiar; hortaliças consumidas; frutas consumidas; itens extras; freqüência de compras; consumiria fruta e hortaliças processadas; porque consome os produtos; o que leva a comprar sempre no mesmo lugar.

As análises dos resultados foram realizadas por meio de estatística descritiva, utilizando-se os recursos do software SAEG Sis temas para Análises Estatísticas (2007), cujo objetivo básico é o de sintetizar uma série de valores da mesma natureza, permitindo dessa forma que se tenha uma visão global das variações dos valores, de modo a organizar e descrever os dados por meio de tabela ou gráficos, utilizando-se o nível de significância de $5 \%$ e desvio de $5 \%$, em torno da proporção da amostra.

Os dados foram analisados segundo o método de amostragem simples ao acaso, e as questões dicotômicas analisadas pelo método de amostragem simples em proporção ou porcentagem, considerando o nível de significância de 5\% de probabilidade, sendo as médias das variáveis comparadas pelo teste Tukey, adotando-se 5\% de probabilidade.

\section{Resultados e Discussão}

\section{Perfil dos produtores agroecológicos no município de Ouricuri}

Os resultados encontrados revelam que em todos os casos as amostras utilizadas para estimar a proporção dos produtores foram representativas de uma população infinita destes. Neste caso, os resultados permitem a 
(RODRIGUES et al., 2015)

extrapolação do comportamento dos produtores na região.

Os resultados da figura 1A demonstram que do total dos entrevistados $50 \%$ destes produtores são do sexo masculino e $50 \%$ do sexo feminino. Estes resultados revelam que com relação aos produtores agroecológicos existe uma igualdade de gênero, com destaque para o empoderamento das mulheres quan to a manutenção familiar e geração de renda, não apenas como ajudante. Este fato revela assim o papel da mulher como protagonista quando se trata deste tipo de agricultura e das atuais relações familiares localizadas no ambiente rural, uma vez que esse público foi por muito tempo estigmatizado por ideais paternalistas e machista, todavia existem outros fatores que também estão intimamente ligado a compreensão e que influencia este resultados, com destaque a ausência de alguns chefes de família em determinadas épocas do ano, visto que, é fato comum a saída de agricultores desta região para trabalhar em outros estados. Outro fator importante neste contexto é o papel de certas ONGs e Movimentos sociais, sendo que estas buscam capacitar o público feminino em diversas áreas agoecológicas, como por exemplo, as hortas comunitárias.

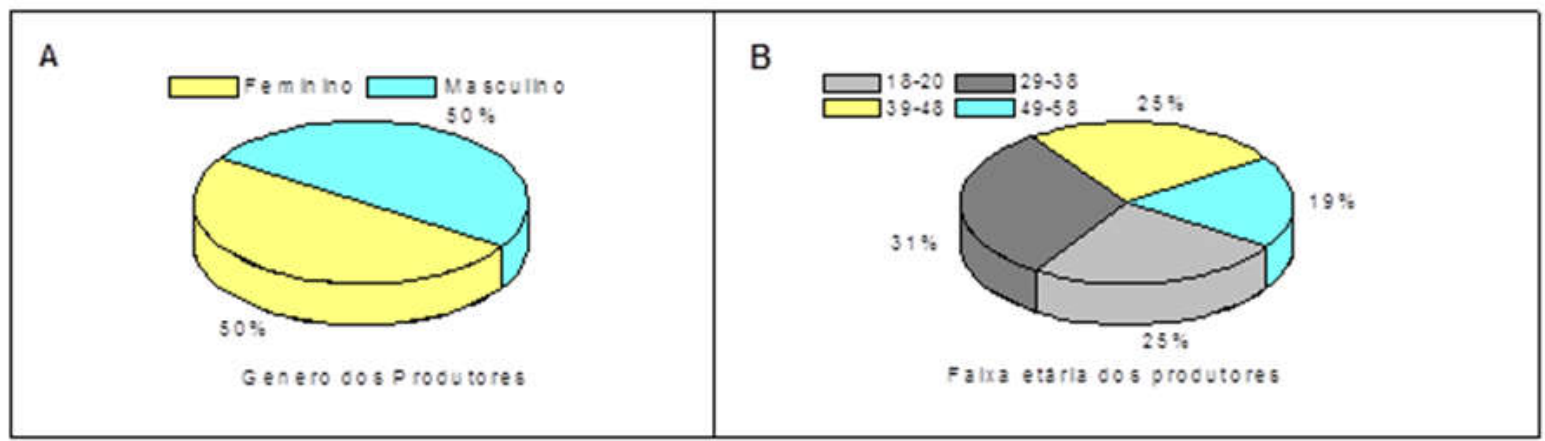

Figura 1: Gênero (A) e Faixa etária (B) dos produtores agroecológicos do município de Ouricuri-PE.

Com relação à faixa etária destes produtores (Figura 1B) foi possível verificar que a maioria dos indivíduos presentes no campo pertencia à faixa etária situada entre 2938 anos (31\%), enquanto que os indivíduos de 18-20 e 39-48 anos representam $25 \%$ do total dos entrev istados e a faixa etária de 49-58 anos apresentaram um índice de 19\% destes. Estes resultados revelam que a maioria dos produtores agroecológicos ( $81 \%)$ possui até 48 anos o que demonstram certa conscientização desta parcela jovem da população em produzir com respeito à natureza. Resultados semelhantes foram obtidos em trabalho realizado com agricultores familiares na Paraíba, onde Ramos et al (2011) relatam que a maioria dos agricultores encontravam na faixa etária de 30-49 anos com uma forte presença dos filhos auxiliando na venda dos produtos.

A figura $2 \mathrm{~A}$ demonstra que a maioria dos produtores agroecológicos do município recebem menos de um salário mínimo (81\%) com a venda dos seus produtos, enquanto que $13 \%$ destes recebem até 1 salário e apenas $6,3 \%$ recebem de 1 a 2 salários mínimos. Estes dados revelam que os produtos agroecológicos ainda carecem de um trabalho de Marketing visando assim um acréscimo no valor de venda dos mesmos. Em trabalho realizado por Godoy \& Anjos (2007) estes autores relatam também o baixo retorno econômico, sendo que nestas pesquisas os dados revelam que os feirantes de Pelotas-RS possuem renda de 1 a 2 salários mínimos. 
(RODRIGUES et al., 2015)

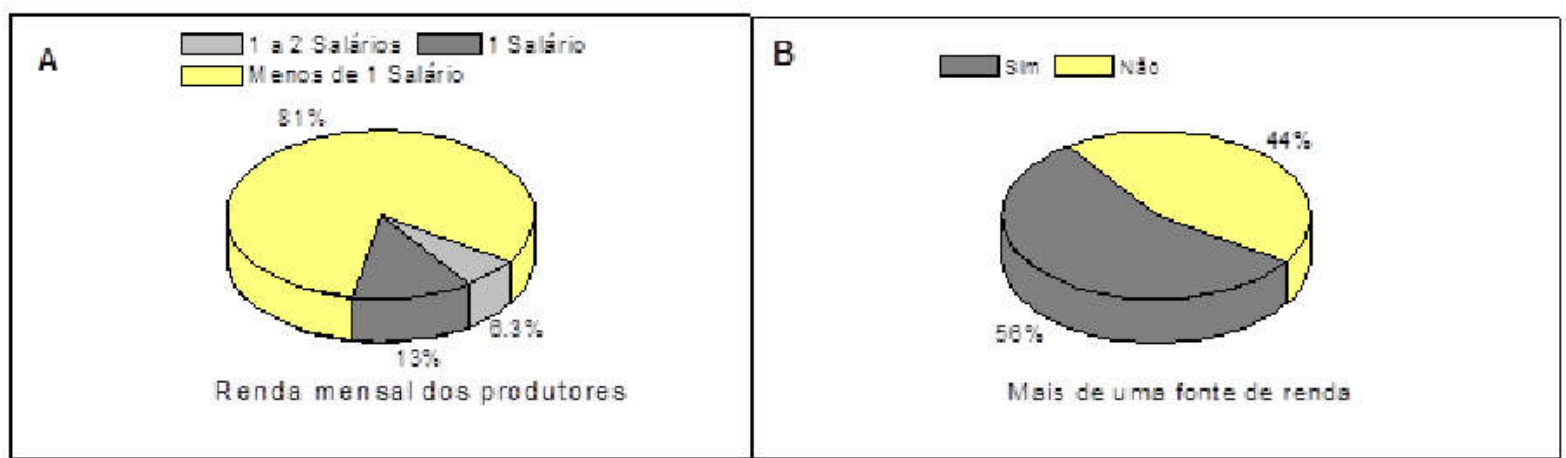

Figura 2: Renda mensal (A) e Mais de uma fonte de renda (B) dos produtores agroecológicos do município de Ouricuri-PE.

Os resultados apresentados na figura $2 \mathrm{~B}$ mostram que $56 \%$ dos agricultores agroecológicos não vivem exclusivamente da agricultura possuindo assim outra fonte de renda, enquanto que $44 \%$ vivem exclusivamente dos recursos gerados pelos produtos agroecológicos. Este fato corrobora a necessidade de buscar estratégias que melhorem a renda destes produtores como forma de fixação do homem no campo.
No que se refere ao grau de escolaridade (figura $3 \mathrm{~A}$ ) dos produtores agroecológicos $75 \%$ destes possuem apenas o $1^{\circ}$ grau incompleto, enquanto que $19 \%$ possuem o segundo grau incompleto e apenas $6,3 \%$ possuem o segundo grau completo, este fato relata a necessidade de políticas voltadas para a capacitação destes produtores.

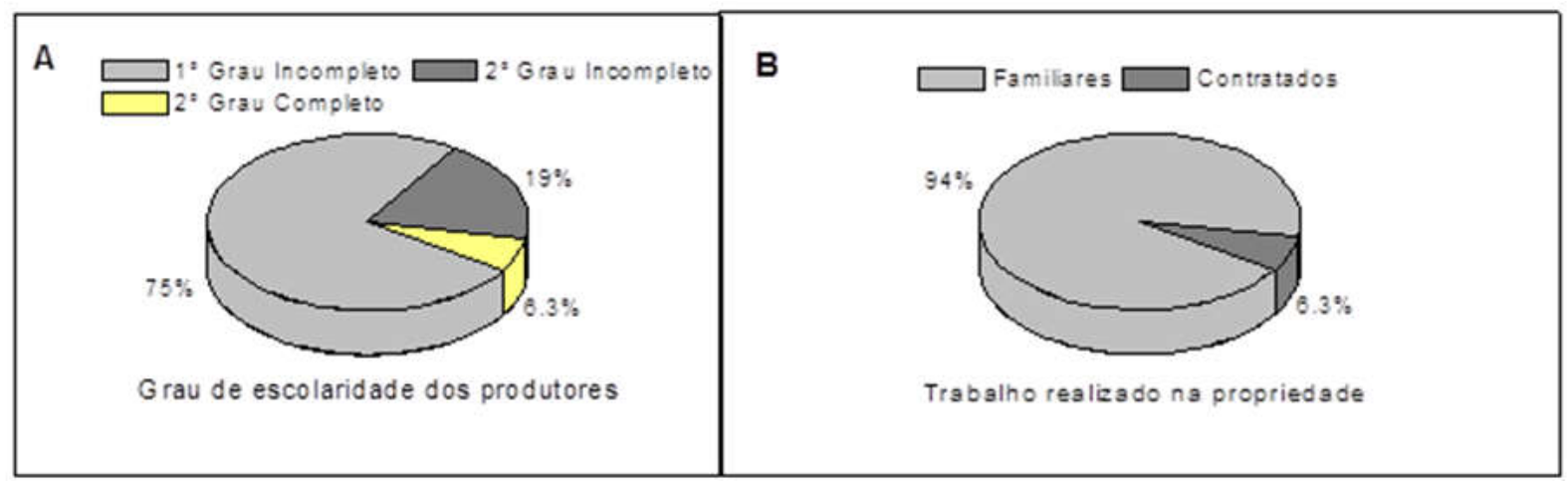

Figura 3: Grau de escolaridade 1(A) e Trabalho realizado na propriedade (B) dos produtores agroecológicos do município de Ouricuri-PE.

$\mathrm{Na}$ figura $3 \mathrm{~B}$ os dados revelam que $94 \%$ destes produtores trabalham exclusivamente com a ajuda dos familiares, enquanto que apenas $6,3 \%$ destes produtores contratam mão de obra especializada para ajudar na condução da sua lavoura.
Com relação ao preço de venda dos produtos agroecológicos (figura 4A) $50 \%$ dos produtores do município de Ouricuri consideraram bons os preços recebidos pelos seus produtos, enquanto que os outros $50 \%$ destes acharam apenas razoáveis os preços recebidos pelos seus produtos. 
(RODRIGUES et al., 2015)

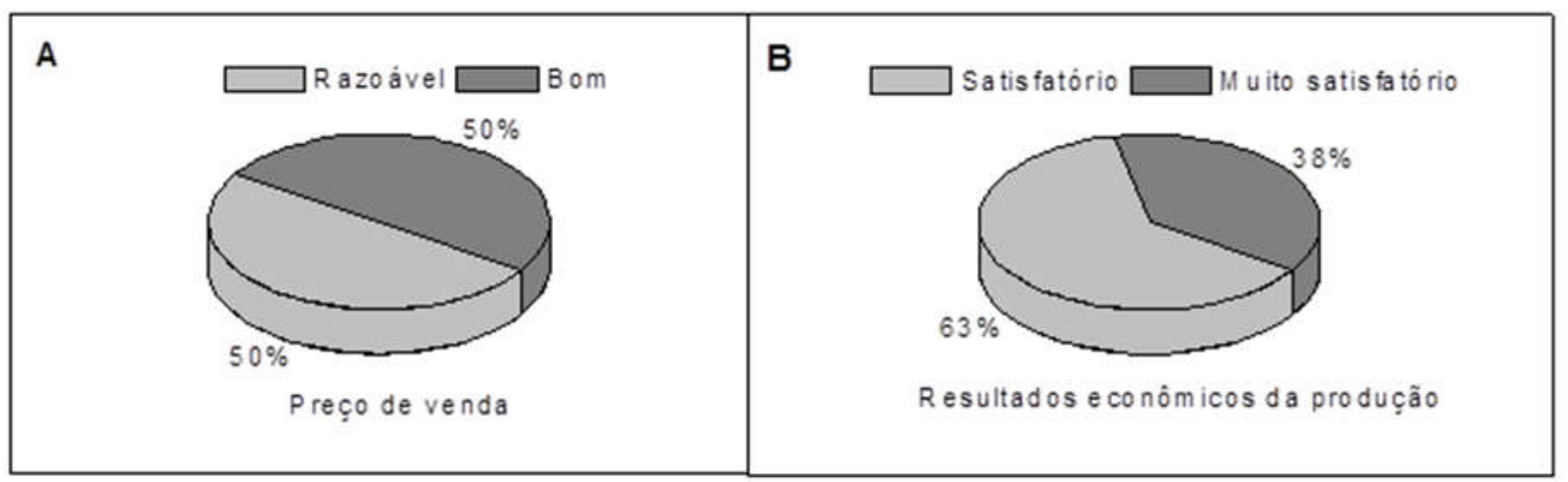

Figura 4: Preço de venda (A) e Resultados econômicos (B) dos produtores agroecológic os do município de OuricuriPE.

Os dados da figura 4B relatam que $63 \%$ destes produtores consideram satisfatórios os resultados econômicos obtidos pelos seus produtos, enquanto que para $38 \%$ destes produtores os resultados econômicos são muito satisfatórios.

Com relação à área da propriedade (figura 5A) os resultados demonstram que
$38 \%$ destes produtores possuem até 1 ha, ou seja, são pequenas propriedades onde predominam a agricultura de subsistência. O estudo relata ainda que $31 \%$ destes agricultores possuem de 1 a 3 ha e outros $31 \%$ com sítios de mais de 4 ha.

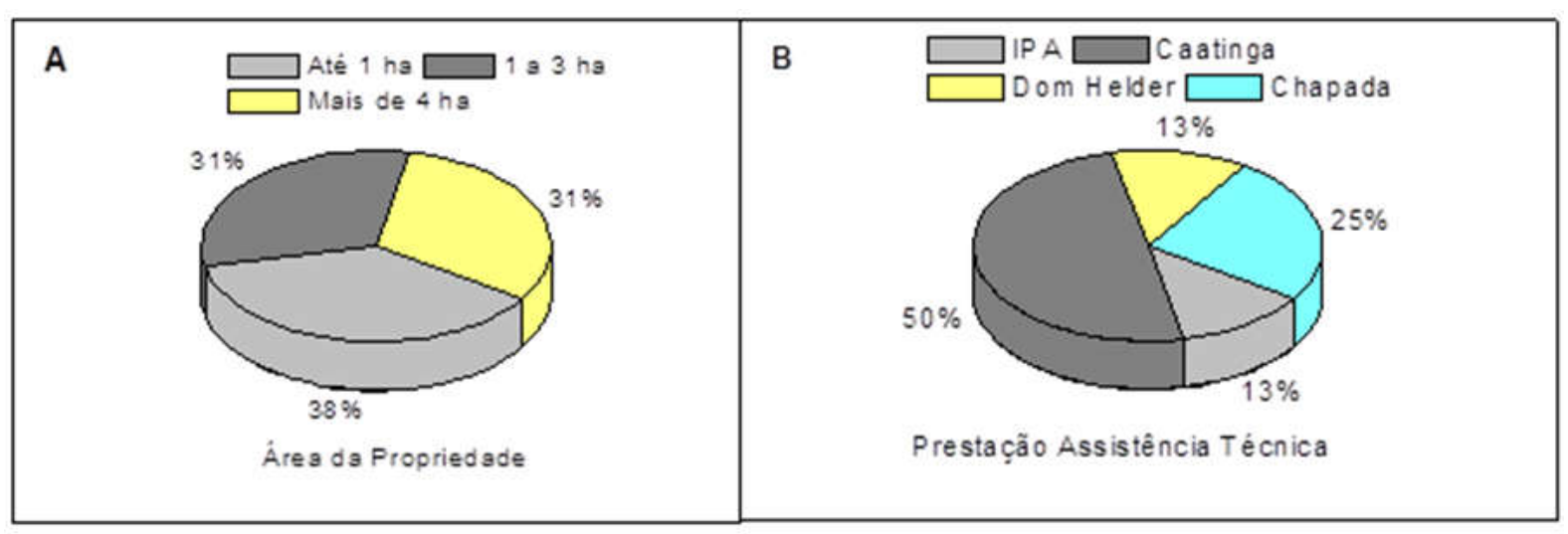

Figura 5: Area da propriedade (A) e Assistência técnica (B) dos produtores agroecológicos do município de OuricuriPE.

Os dados da figura 5B referem-se à assistência técnica prestada aos produtores, a maior parte destes (50\%) são assistidos pela ONG Caatinga, enquanto que $25 \%$ recebem assistência técnica da ONG Chapada, o projeto Dom Elder Câmara responde por apenas $13 \%$ desta assistência. Com relação aos órgãos do governo o Instituto Agronômico de Pernambuco (IPA) prestam assistência a 13\% destes agricultores. Os dados revelam uma forte participação de ONGs na prestação de assistência técnica e capacitaçõ es para estes pequenos agricultores.
No que se refere ao tempo de cultivo de produtos agroecológicos (Figura 6A) 31\% dos entrevistados cultivam produtos agroecológicos ha menos de um ano, enquanto que $25 \%$ destes cultivam de 1 a 3 anos e os produtores com mais de quatro anos de cultivo agroecológico respondem por $44 \%$. Este fato revela que o cultivo de produtos agroecológicos no município de Ouricuri é recente e com tendência ao crescimento, visto que, $100 \%$ dos entrevistados relatam estarem satisfeitos com a agroecologia e que a sua 
(RODRIGUES et al., 2015)

produtividade aumentou com o emprego destas técnicas.

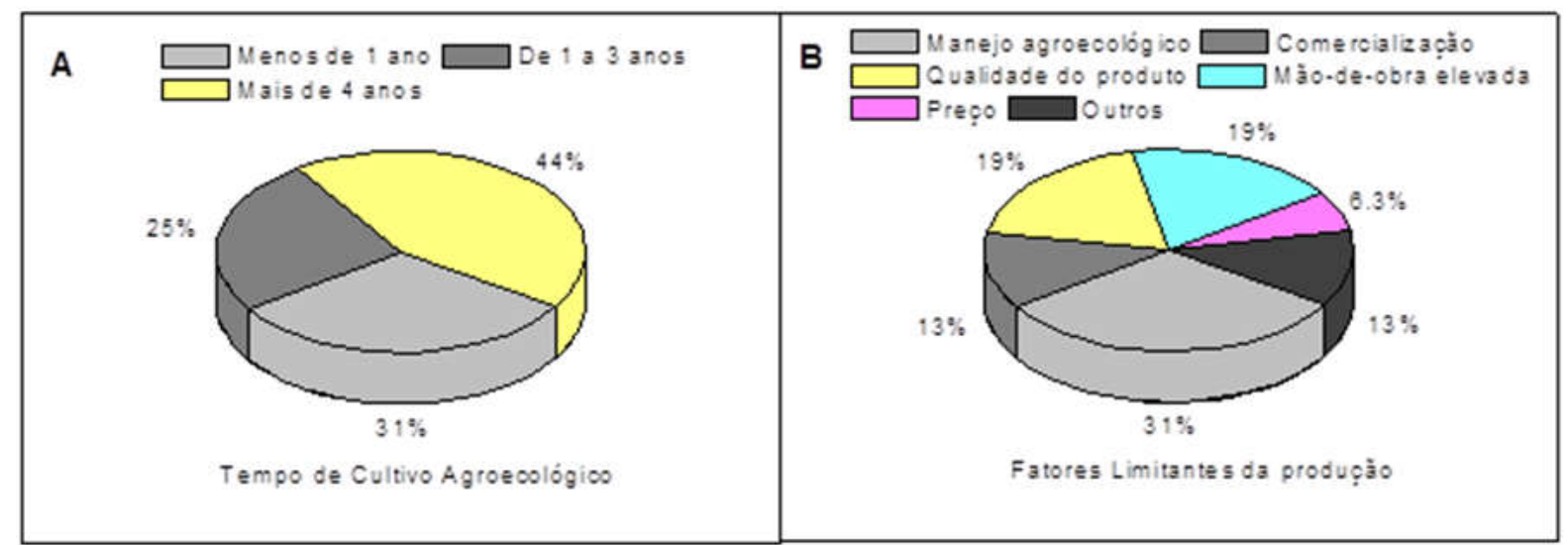

Figura 6: Tempo de cultivo agroecológico (A) e Fatores limitantes da produção (B) dos produtores agroecológicos do município de Ouricuri-PE.

A figura $6 \mathrm{~B}$ demonstra que existem alguns fatores limitantes para que outras pessoas também possam produzir produtos agroecológicos, este fato deve-se a diversos entraves na produção. A pesquisa revelou que $31 \%$ dos entrevistados tem dificuldade no manejo agroecológico, além deste necessitar de mão de obra elevada o qual é limitante para $19 \%$ destes agricultores. Outros fatores dificultam a produção como a qualidade do produto (19\%) e a comercialização (13\%). Com relação aos preços pagos apenas $6,3 \%$ destes produtores não estão satisfeitos com os valores de mercado.

Com relação aos preços pagos pelos produtos agroecológicos os dados demonstram que para a maioria dos produtores agroecológicos $(69 \%)$ relatam que os seus produtos deveriam possuir preços diferenciados, enquanto que para $31 \%$ destes não deveria existir um diferencial de preço entre produtos agroecológicos e convencionais (figura 7A).

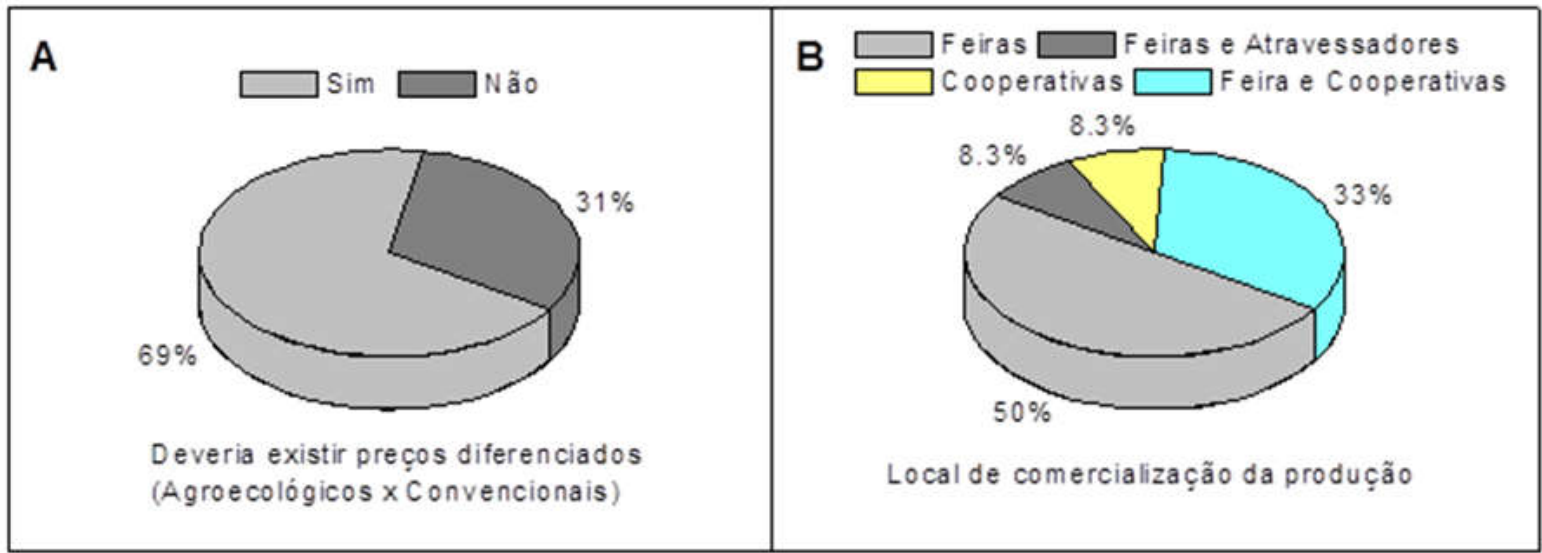

Figura 7: Preços diferenciados (A) e Local de comercialização (B) dos produtores agroecológicos do município de Ouricuri-PE.

No que se refere ao local de comercialização dos produtos (figura 7B) $50 \%$ destes produtores comercializam os produtos exclusivamente nas feiras locais, enquanto que $33 \%$ associam a venda entre feiras e Cooperativas, outros comercializam os seus produtos entre a feira e atravessadores $(8,3 \%)$ e apenas $8,3 \%$ destes vendem apenas para Cooperativas. 
(RODRIGUES et al., 2015)

$\mathrm{Na}$ figura 1 encontram-se os dados relativos à produção destes agricultores agroecológicos, os resultados demonstram uma ampla variedade de produtos, sendo que $32 \%$ produzem na sua propriedade frutas e hortaliças. Existe uma grande diversidade de produtos, sendo que $13 \%$ destes produtores trabalham com produtos de origem animal associados a produtos de origem vegetal, os dados relatam que $6 \%$ destes trabalham exclusivamente com polpa de frutas. Segundo Godoy \& Anjos (2007) a estratégia de diversificação na produção é muito utilizada como forma de gerar um maior retorno econômico, estes autores relatam em seu trabalho a mesma estratégia adotada por feirantes ecológicos de Pelotas-RS.

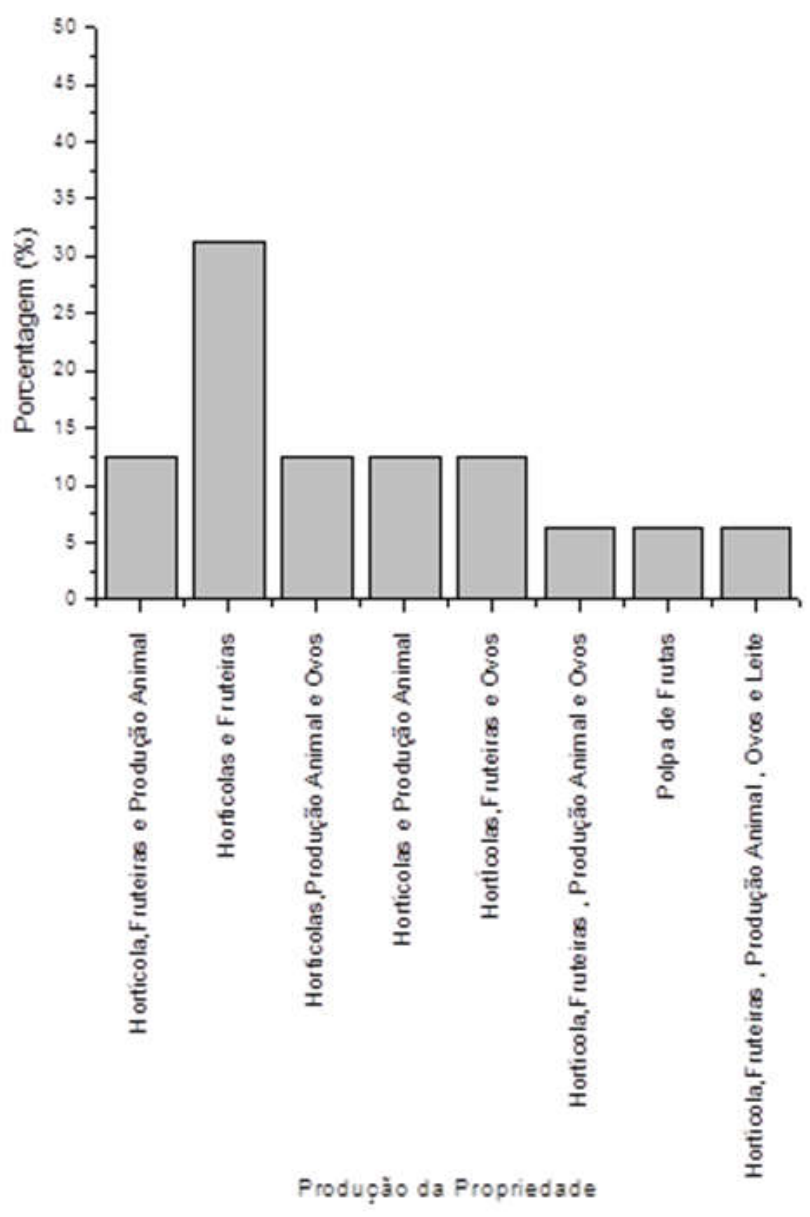

Grá fico 1: Produção dos agricultores agroecológicos do município de Ouricuri-PE.

Perfil dos consumidores de produtos agroecológicos e convencionais do município de Ouricuri

Os resultados encontrados revelam que em todos os casos as amostras utilizadas para estimar a proporção dos consumidores foram representativas de uma população infinita destes. Neste caso, os resultados permitem a extrapolação do comportamento dos consumidores na região.

Os resultados da figura $1 \mathrm{~A}$ demonstram que a maioria dos consumidores agroecológicos entrevistados são do sexo feminino $(73,33 \%)$, enquanto que os consumidores do sexo masculino respondem por apenas 26,66\%. Entretanto quando se analisa os consumidores de produtos 
(RODRIGUES et al., 2015)

convencionais encontram-se resultados diferentes, visto que, $85,10 \%$ destes entrevistados são do sexo masculino e apenas $14,90 \%$ são do sexo feminino. Estes resultados revelam que a mulher preocupa mais com a aquisição de alimentos de origem mais saudáveis.
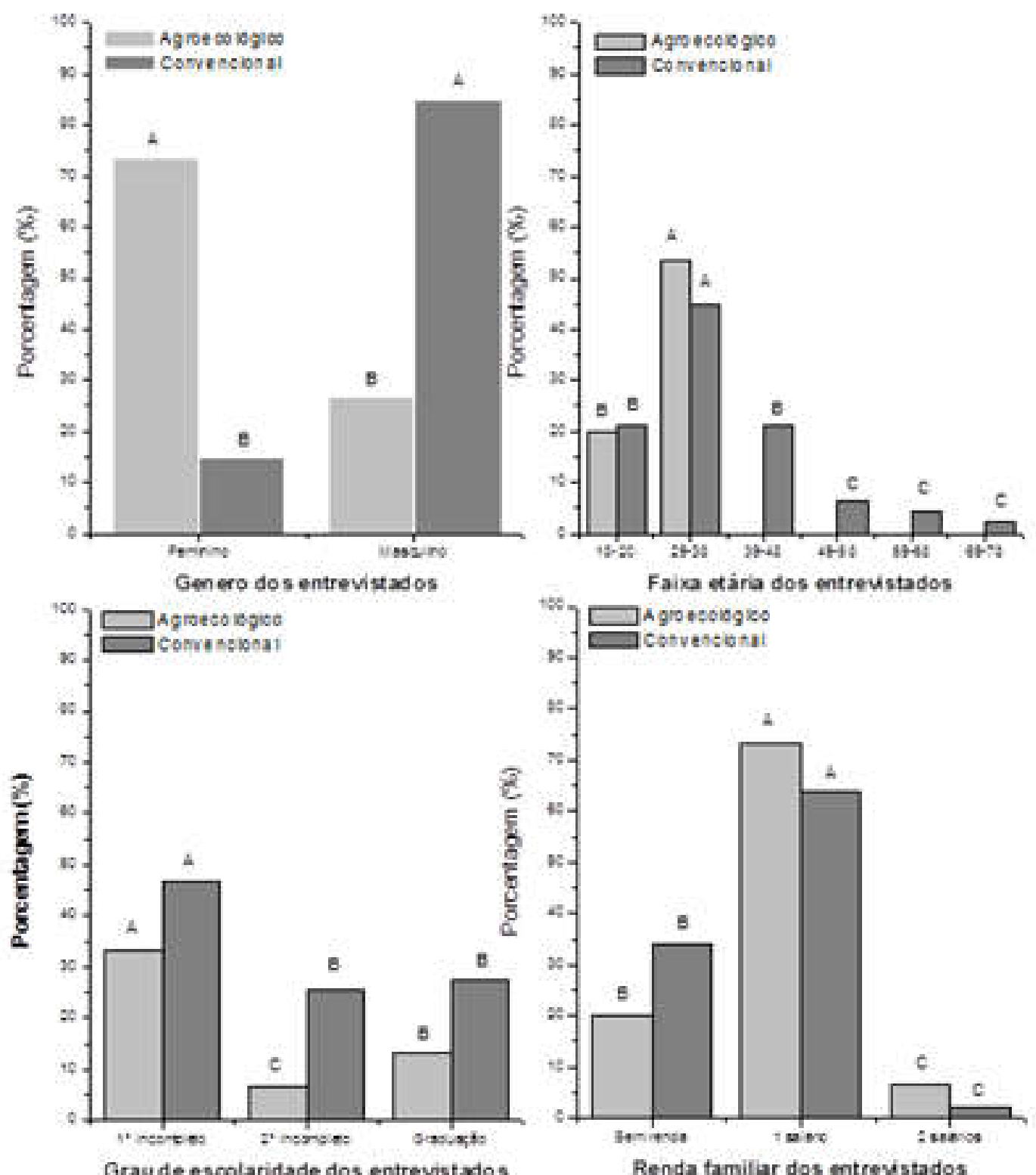

Figura 1: Gênero (A); Faixa etária (B); Grau de escolaridade (C) e Renda familiar (D) dos consumidores de produtos agroecológicos e convencionais do município de Ouricuri-PE. As médias não seguidas pela mesma letra na coluna diferem entre si pelo teste de Tukey em nível de $5 \%$ de probabilidade de erro.

Com relação à faixa etária (figura 1B) verificou-se que a maioria dos consumidores agroecologicos tem idade entre 29-38 anos $(53,33 \%)$, enquanto que para os consumidores na faixa etária de 18-20 anos respondem por apenas $20 \%$ deste consumo, este padrão de consumo revela que os consumidores de produtos agroecológicos são 
(RODRIGUES et al., 2015)

pessoas jovens. Com relação ao consumo de produtos convencionais todas as faixas etárias possuem um percentual de entrevistados, sendo que para a idade entre 29-38 representa $44,68 \%$ destes, enquanto que para as faixas etárias de $18-20$ e 39-48 os entrevistados respondem por $20 \%$, as demais respondem por $6 \%$ ou menos.

A respeito do grau de escolaridade dos consumidores (figura 1C) independente deste ha uma maior porcentagem de consumidores de produtos convencionais, sendo que a maioria dos consumidores do município (46, $80 \%$ ) não possuem o $1^{\circ}$ grau completo, enquanto que $25,53 \%$ possuem apenas o $2^{\circ}$ grau incompleto e apenas $27,65 \%$ possuem uma graduação.

No que se refere à renda dos consumidores figura 1D, os consumidores de produtos agroecológicos possuem uma maior renda quando comparados aos consumidores de produtos convencionais. Entretanto os dados revelam que a maioria destes consumidores possuem renda de apenas um salário mínimo, enquanto que $20 \%$ destes não possuem renda fixa e apenas $6,66 \%$ possuem renda de dois salários mínimo.

A figura $2 \mathrm{~A}$ demonstram os dados relativos a quantidade de moradores na residência dos entrevistados, os resultados revelam que não houve diferenças estatísticas entre os consumidores de produtos agroecológicos e convencionais para os entrevistados que moram com até 3 pessoas, sendo que aproximadamente $33,33 \%$ moram com mais de 1 pessoa e 48,98\% moram com até 3 pessoas. Entretanto para os entrevistados que moram com mais de 3 pessoas, os dados revelam que existe uma porcentagem maior para consumidores de produtos convencionais, sendo que estes respondem por $48,98 \%$, enquanto que os consumidores de agroecológicos respondem por apenas $32 \%$ destes entrevistados.
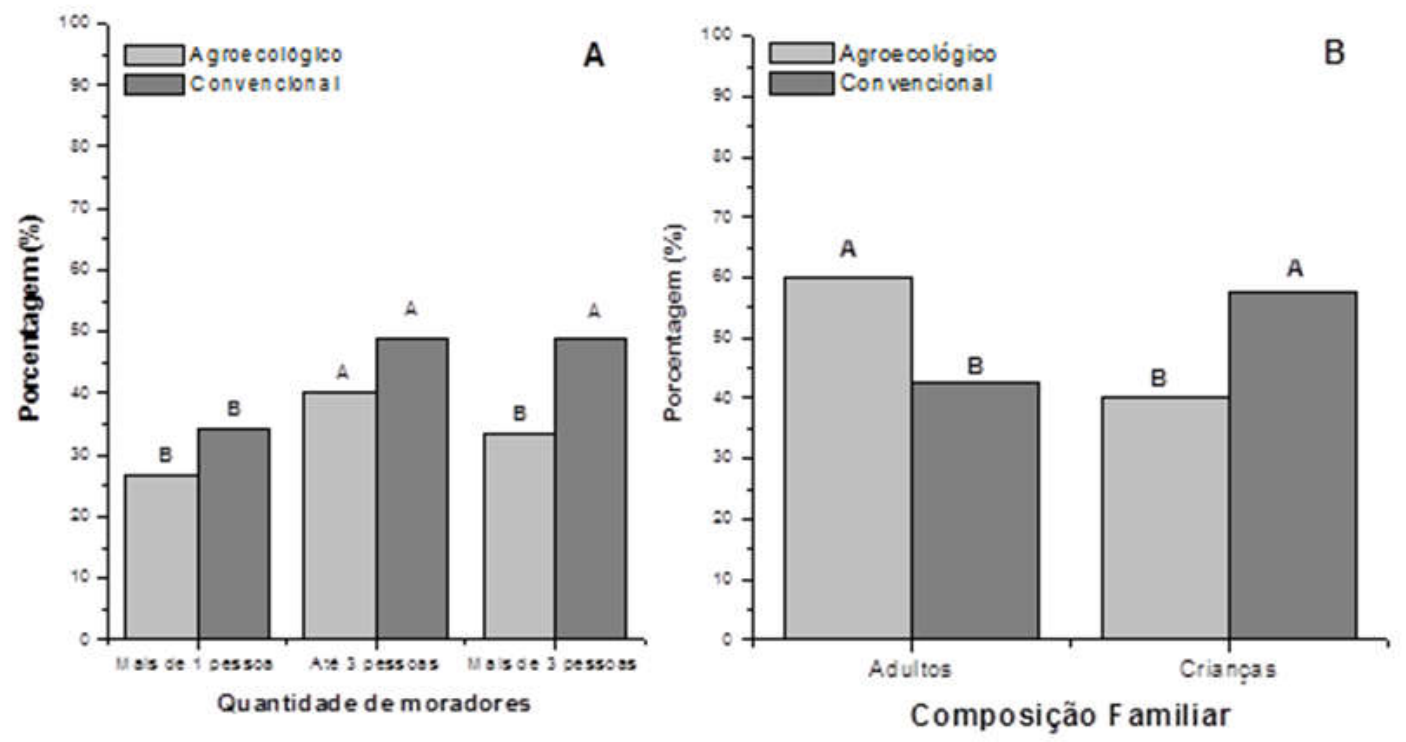

Figura 2: Quantidade de moradores (A) e Composição familiar (B) dos consumidores de produtos agroecológicos e convencionais do município de Ouricuri-PE. As médias não seguidas pela mesma letra na coluna diferem entre si pelo tes te de Tukey em nível de $5 \%$ de probabilidade de erro.

Com relação à composição familiar destes consumidores (figura 2A), os consumidores de produtos agroecológicos possuem uma maior quantidade de adultos, enquanto que para os consumidores de produtos convencionais as famílias possuem mais crianças. Estes dados revelam uma preocupação devido ao fato das crianças consumirem produtos convencionais e não os 
(RODRIGUES et al., 2015)

agroecológicos, o que poderia acarretar em um maior risco a saúde destes.

Com relação às frutas consumidas pelos entrevistados (figura 3A) os dados mostram que a maioria destes adquire uma maior porcentagem de produtos convencionais quando comparados aos agroecológicos, além disso, estes consumidores estão sujeitos a safras e compras de produtos vindos de outros mercados, o que dificulta a análise destes dados.
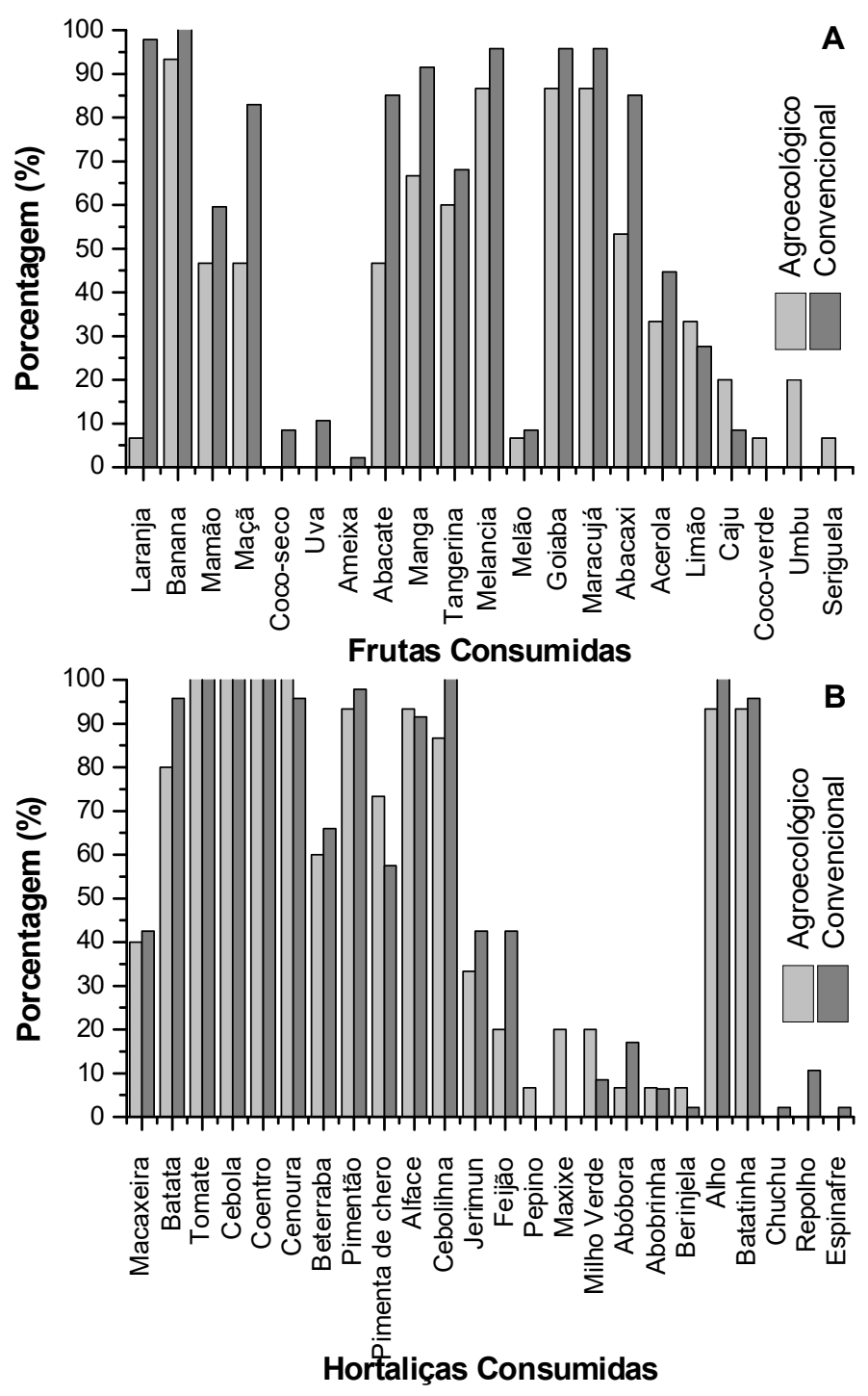

Figura 3: Frutas consumidas (A) e Hortaliças consumidas (B) pelos consumidores de produtos agroecológicos e convencionais do município de Ouricuri-PE. As médias não seguidas pela mesma letra na coluna diferem entre si pelo tes te de Tukey em nível de $5 \%$ de probabilidade de erro.

Com relação às hortaliças adquiridas no ato da compra (figura 3B), os consumidores agroecologicos $100 \%$ destes compraram cebola, co entro, tomate e cenoura, 93,33\% adquirem batatinha, alho, alface e pimentão, as demais hortaliças respondem por diferentes porcentagens. Com relação aos consumidores de produtos convencionais $100 \%$ destes adquirem tomate, alho, coentro, cebola e cebolinha, 95, 74\% consomem 
(RODRIGUES et al., 2015)

batatinha, beterraba, batata e cenoura, os demais produtos respondem por diversas porcentagens, quando comparam-se os produtos agroecológicos e convencionais existe uma maior aquisição de produtos convencionais, fato este deve-se à baixa oferta de produtos agroecoló gicos.

A figura 4A demonstram os dados relativos à frequência de aquisição dos produtos pelos entrevistados, sendo que independente do tipo do produto há uma maior porcentagem de aquisição mensal, sendo que 93,33\% adquirem produtos agroecológicos e $\quad 89,36 \%$ produtos convencionais. As compras semanais respondem por uma menor porcentagem, sendo que 6,66\% dos entrevistados adquirem produtos agroecológicos e $10,63 \%$ produtos convencionais.
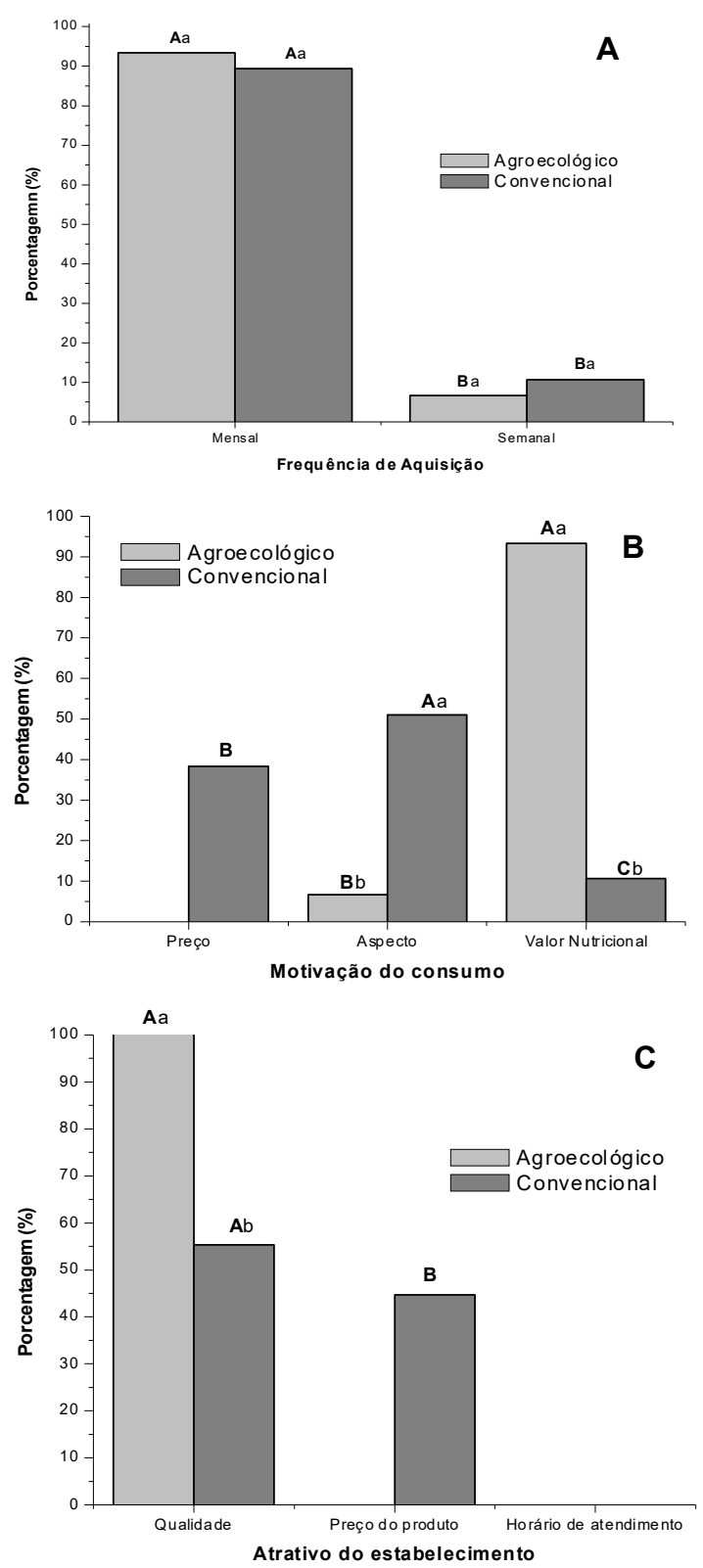

Figura 4: Frequência de aquisição (A), Motivação para o consumo (B) e atrativo do estabelecimento (C) pelos consumidores de produtos agroecológicos e convencionais do município de Ouricuri-PE. As médias não seguidas pela mesma letra na coluna diferem entre si pelo teste de Tukey em nível de 5\% de probabilidade de erro. 
(RODRIGUES et al., 2015)

Com relação à motivação para o consumo (figura 4B), os dados revelam que para os entrevistados o maior consumo de produtos agroecologicos deve-se pelo valor nutricional $(93,33 \%)$, enquanto que as maiores motivações em adquirir produtos convencionais são os preços e o aspecto.

A figura $4 \mathrm{C}$ demonstram os resultados relativos ao atrativo em adquirir os produtos na feira livre, para os consumidores de agroecológicos $100 \%$ destes são atraídos pela qualidade dos produtos, enquanto que para os consumidores de produtos agroecológicos os atrativos são a qualidade $(55,39 \%)$ e o preço do produto $(44,61 \%)$, além disto estes consumidores não reclamaram com relação ao horário de atendimento.

\section{Conclusões}

Os resultados obtidos na primeira etapa do trabalho demonstram que a maioria dos produtores entrevistados possuem baixa renda familiar, com faixa etária de 29 a 38 anos. Estes produtores está há pouco tempo utilizando técnicas agroecológicas, entretanto, os mesmos consideram que a sua produtividade aumentou com a adoção do sistema agroecológico, além destes considerarem satisfatórios os resultados financeiros obtidos. Os produtores relatam ainda que com relação à prestação de assistência técnica a ONG CAATINGA (Centro de Assessoria e Apoio a Trabalhadores/as e Instituições Não Governamentais Alternativas) é a instituição que procura solucionar os problemas enfrentados por eles através de capacitações e acompanhamento técnico.

Com relação à segunda etapa do projeto, ao qual foi as entrevistas com os consumidores de produtos agroecológicos e convencionais, os resultados obtidos rev elam que são as mulheres as preocupadas em adquirirem produtos agroecológicos, sendo a maioria da faixa etária de 29-38 anos com apenas o $1^{\circ}$ grau incompleto e com renda familiar de 1 salário mínimo. Com relação à aquisição destes produtos os dados relatam uma maior aquisição de convencionais, este fato deve-se a pequena diversidade de produtos agroecológicos oferecidos na feira livre. Quando os consumidores foram questionados sobre o motivo da compra de produtos agroecológicos houve consenso de quase todos em função da qualidade deste produto.

Fazendo um paralelo entre as duas fases da pesquisa, pode-se constatar que o tanto produtores, quanto consumidores agroecológicos estão preocupados em melhorar o nível de qualidade de vida, partindo do cuidado com a alimentação, sendo importante ressaltar que um dos elementos que marca o produtor agroecológico é o consumo familiar, sendo a produção excedente comercializada e por conta disso a chegada do produto no mercado começa a ganhar intensidade.

Com base nos dados tratados ao longo do texto, compreende-se que há uma relação muito próxima entre consumidores e produtores, considerando faixa-etária, escolaridade, poder aquisitivo, produção e produtos consumidos, todavia a produção ainda não atende as necessidades e procura dos consumidores, isso devido a limitações climáticas e geográficas e de investimento financeiro, por conta desse elemento a procura por produtos convencionais ainda possuem um grande percentual na região analisada.

Acredita-se que o maior resultado do estudo está na compreensão de que é possível trabalhar com a produção agroecológica na região e que existe mercado para escoar a mercadoria, necessitando de maior investimento e ações de políticas públicas para melhorar e/ou ampliar as condições de produção. Os dados apontam para a construção de um plano de negócio estruturado e acompanhamento sistemático para a melhoria da produção e o atendimento com quantidade e qualidade ao público consumidor.

\section{Referências}

ASSIS, R. L. de. Diagnóstico da agricultura orgânica no Estado do Rio de Janeiro e propostas para a sua difusão. Itaguaí, Dissertação (Mestrado) Universidade Federal Rural do Rio de Janeiro. 154 p, 1993.

COSTA, M. B. B. da. Agricultura Moderna e sua Crítica: Uma Saída em Relação as Vertentes da 
(RODRIGUES et al., 2015)

Agricultura Alternativa. In: Seminário de Pesquisa em Agricultura Alternativa, Londrina, Fundação Instituto Agronômico do Paraná (IAPAR), p. 6891, 1987.

GODOY, W.I., ANJOS, F.D. O perfil dos feirantes ecológicos de Pelotas-RS. Rev. Bras. Agroecologia, v.2, n.1, Fev. 2007.

JESUS, E. L. de. Histórico e Filosofia da Agricultura Alternativa. Proposta, Rio de Janeiro, 27: 34-40, 1985.

JESUS, E. L. de. Da Agricultura Alternativa à Agroecologia: Para além das disputas conceituais. Agricultura Sustentável, Jaguariúna, 1-2: 13-27, 1996.

MENEZES, T., SILVEIRA, F.G., MAGALHÃES, L.C.G., TOMICH, F.A., VIANNA, S.W. Gastos alimentares nas grandes regiões urbanas do Brasil: aplicações do modelo AID aos microdados da POF 1995/1996 IBGE. Brasília: IPEA, 21 p, 2002.

MINISTÉRIO DE MINAS E ENERGIA. Secretaria de Geologia, Mineração e Transformação Mineral. Projeto Cadastro de Fontes de Abastecimento por água subterrânea: Estado de Pernambuco Diagnóstico do Município de Ouricuri, 2005, 32 p.

RAMOS, D.A., COELHO, G.D., VITAL, A.F.M., LOPES, E.S.A., SANTANA, A.C.A. Perfil dos agricultores familiares das feiras agroecológicas de Congo-PB e Monteiro-PB. Caderno de Agroecologia - ISSN 2236-7934, v. 6, n.2, dez 2011.

REGMI, A., DYCK, J. Effects of urbanization on global food demand; $<$ http://www.ers.usda.gov/publications/wrs011/wrs 001e.pdf, 2004.

SAABOR, A., ROJO, F. O que pensa o consumidor. Revista SuperHíper, São Paulo, 158168, 2001.

SAEG. Sistemas para Análises Estatísticas. Versão 9.1, Viçosa: Fundação Arthur Bernardes - UFV, 2007.

SOUZA, R.A.M., SILVA, R.O.P., MANDELLI, C.S., TASCO, A.M.P. Comercialização Hortícola: Análise de alguns setores do mercado varejista de São Paulo. Informações Econômicas, São Paulo, 28 (10):33-36, 1998.

ZOLDAN, P.; KARAM, K. F. Estudo da dinâmica da comercialização de produ to s orgânicos em Santa Catarina. Florianópolis: Instituto Cepa/SC, 181 p, 2004. 